\title{
Interferência de plantas daninhas em sorgo sacarino em diferentes espaçamentos no semiárido mineiro
}

\author{
Renato Mendes de Oliveira(1); Ignacio Aspiazú(2); Arley Figueiredo Portugal(3); Karen \\ Marcelle de Jesus Silva ${ }^{(4)}$; Alexandre Ferreira da Silva ${ }^{(5)}$; Abner José de Carvalho ${ }^{(6)}$.
}

(1) Doutorando em Produção Vegetal; Universidade Estadual de Montes Claros; Janaúba, Minas Gerais; renatoagronomo@hotmail.com; (2; 6) Professor; Universidade Estadual de Montes Claros; (3; 5) Pesquisador; Empresa Brasileira de Pesquisa Agropecuária - EMBRAPA; ${ }^{4}$ Doutoranda em Fitotecnia; Universidade Federal de Lavras.

RESUMO: Objetivou-se com o trabalho determinar o período anterior à interferência (PAI), período total de prevenção a interferência (PTPI) e período crítico de prevenção a interferência (PCPI) das plantas daninhas na cultura do sorgo sacarino, cultivar BRS 506. O trabalho foi conduzido na Fazenda Experimental da Embrapa Milho e Sorgo, em Nova Porteirinha, MG. Os tratamentos foram constituídos pela combinação de dois espaçamentos entre linhas do sorgo $(0,50$ e $0,70 \mathrm{~m})$ e dez períodos de controle ou de convivência das plantas daninhas com a cultura $(0,7,14,21,28,35$, 42, 49, 56 e 120 dias após a emergência). O PAI foi de 19 e 24 DAE para o espaçamento $0,5 \mathrm{~m}$ e $0,7 \mathrm{~m}$ respectivamente. O PTPI para produtividade de massa verde total foi, 17 e 10 DAE para os espaçamentos de $0,5 \mathrm{~m}$ e $0,7 \mathrm{~m}$ respectivamente. Não houve PTPI para os demais parâmetros. Não houve PCPI para nenhum dos parâmetros avaliados (PAI > PTPI).

Termos de indexação: Sorghum bicolor, competição, períodos de interferência.

\section{INTRODUÇÃO}

O sorgo sacarino vem sendo considerado uma ótima opção, sob os pontos de vista agronômico e industrial, para a produção de etanol. A cultura tem sido alvo de interesse, pois se aproxima dos níveis de produção de cana-de-açúcar em áreas de menor pluviosidade e, possivelmente, com menos fertilização. O potencial de utilização do sorgo sacarino na produção de etanol foi verificado por Durães (2011), que obteve de 50 a 77 litros de etanol por tonelada de massa verde da planta, com ATR (açúcares totais recuperáveis) de 80 a 127 kg de açúcar extraídos por tonelada de massa verde.

Estudos mais aprofundados para a cultura do sorgo sacarino ainda são incipientes. Um ponto importante a ser pesquisado é a questão da competição que ocorre entre a cultura e as plantas daninhas. Sabe-se que a presença de plantas daninhas na área de cultivo acarreta efeitos diretos na cultura, como a ocorrência de competição, efeitos alelopáticos, depreciação do produto, dentre outros, justificando assim a importância do estudo dos períodos de interferência das plantas daninhas sob a cultura.

Outro fator importante no manejo da cultura do sorgo sacarino que deve ser mais bem estudado e que afeta o grau de interferência das plantas daninhas sobre a cultura é o espaçamento entre plantas, visto que o mesmo pode ser manejado a fim de favorecer o desenvolvimento da cultura em detrimento das plantas daninhas. Para o sorgo forrageiro e o sorgo granífero, diversos autores reportaram a importância do arranjo de plantas na obtenção de maiores rendimentos (Albuquerque et al., 2011; Baumhardt e Howell, 2006; Jones e Johnson, 1997). Esses autores demonstraram aumento na produtividade de grãos e, ou, matéria seca em função do arranjo de plantas na área, entretanto, para o sorgo sacarino, experimentos com essas informações são incipientes.

De maneira geral, todo manejo empregado na área irá influenciar tanto plantas cultivadas quanto plantas daninhas.

Dessa forma, objetivou-se com o trabalho determinar o período anterior à interferência (PAI), o período total de prevenção à interferência (PTPI) e o período crítico de prevenção à interferência (PCPI) das plantas daninhas na cultura do sorgo sacarino, cultivar BRS 506, em dois espaçamentos.

\section{MATERIAL E MÉTODOS}

O trabalho foi conduzido na Fazenda Experimental da EMBRAPA MILHO E SORGO, localizada em Nova Porteirinha, Norte de Minas Gerais. Os tratamentos foram constituídos pela combinação de dois espaçamentos entre linhas do sorgo $(0,50$ e $0,70 \mathrm{~m})$ e 10 períodos de controle ou de convivência das plantas daninhas com a cultura $(0,7,14,21,28,35,42,49,56$ e 120 dias após a emergência), em que para os períodos de controle a cultura foi mantida livre de plantas daninhas até 0 
período considerado, e para os períodos de convivência, a cultura foi mantida na presença das plantas daninhas até os mesmos períodos, sendo mantida sem plantas daninhas até a colheita. O controle das plantas daninhas foi realizado sempre por meio de capina manual. $O$ delineamento experimental utilizado foi o de blocos ao acaso, em esquema fatorial $2 \times 10$.

O preparo do solo foi convencional, tendo sido realizada uma aração e duas gradagens em préplantio. O sorgo, da cultivar BRS 506, foi semeado manualmente, com posterior desbaste para ajuste do estande para cerca de 100.000 plantas ha- 1 .

Foram avaliadas altura de plantas, diâmetro de colmo, peso da parcela, peso de 10 plantas, massa de caldo, volume de caldo e sólidos solúveis. Os dados foram verificados quanto à normalidade e homogeneidade e submetidos à análise de variância pelo teste $F$. No caso de significância, os dados foram submetidos à análise de regressão. Os dados das variáveis analisadas de cada tratamento (períodos de controle e convivência) foram ajustados ao modelo de regressão não linear, utilizando-se a equação proposta por Kozlowski et al. (2002), determinando-se 0 período de interferência das plantas daninhas.

\section{RESULTADOS E DISCUSSÃO}

As variáveis sólidos solúveis, massa do caldo e peso de 10 plantas não foram estatisticamente afetadas pelos espaçamentos utilizados ou pelos períodos de controle ou convivência com as plantas daninhas.

A produtividade total de massa verde foi afetada tanto pelo espaçamento quanto pelos períodos de controle e convivência. Para ambos os espaçamentos estudados, a resposta da característica em função dos períodos de interferência se ajustou a modelos de regressão não lineares. Para o espaçamento de $0,5 \mathrm{~m}$, foram encontrados os valores 17 e 21 dias após a emergência (DAE) para o PTPI e 0 PAI, respectivamente (Figura 1 ).

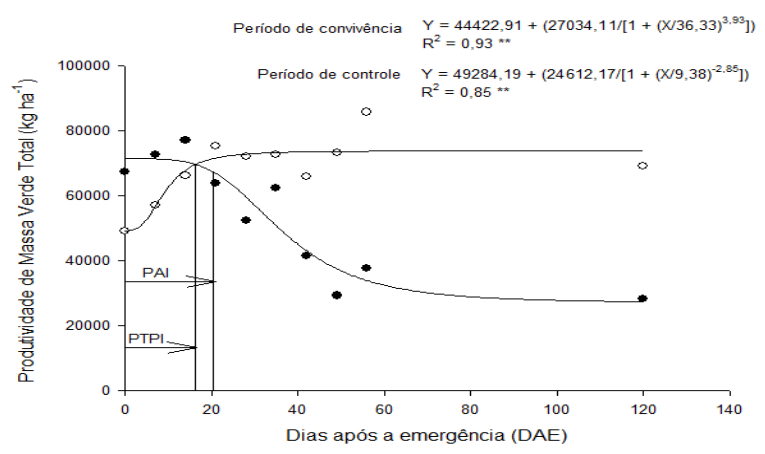

Figura 1. Produtividade de massa verde total na cultura do sorgo sacarino em função dos períodos de controle e de convivência com as plantas daninhas no espaçamento $0,5 \mathrm{~m}$. Nova PorteirinhaMG, 2012/13.

Para o espaçamento de $0,7 \mathrm{~m}$, os valores de PTPI e PAl encontrados foram de 10 e 19 DAE, respectivamente (Figura 2). Esses resultados sugerem que a cultura do sorgo sacarino (BR 506) pode conviver com a comunidade infestante de plantas daninhas, sem perdas significativas na produtividade de massa verde total por 21 dias após a emergência utilizando-se o espaçamento de 0,5 $\mathrm{m}$, e por 19 dias no espaçamento de $0,7 \mathrm{~m}$.

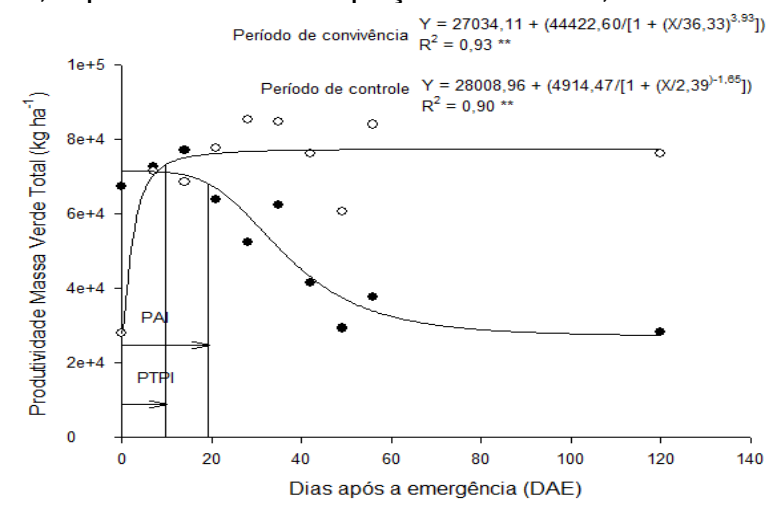

Figura 2. Produtividade de massa verde total na cultura do sorgo sacarino em função dos períodos de controle e de convivência com as plantas daninhas no espaçamento $0,7 \mathrm{~m}$. Nova PorteirinhaMG, 2012/13.

Para ambos os espaçamentos, os valores de PAI foram maiores que os de PTPI, não sendo possível se estimar o PCPI. Rodrigues et al. (2010), em trabalho com o sorgo granífero BRS 310 também não encontraram o PCPI.

De acordo com Pitelli \& Durigan (1984), quando o PCPI não é encontrado, o controle das plantas daninhas em uma época é suficiente, desde que este controle seja feito entre o término do PAI e o término do PTPI, possibilitando que a cultura expresse seu potencial produtivo. Este controle pode ser feito por meio de capina manual ou utilizando-se herbicidas pós-emergentes sem efeito residual. Há também a possibilidade de se usar um herbicida pré-emergente com um efeito residual que ultrapasse o PTPI (Carvalho \& Velini, 2001).

O aumento do período de convivência com as plantas daninhas causou redução linear na altura de plantas de sorgo (Figura 3). Esse resultado sugere que a competição promovida pelas plantas daninhas por recursos como luz, água e nutrientes cresceu com o aumento do período de convivência delas com a cultura, provocando prejuízos ao crescimento das plantas de sorgo. Koslowsky et al. (2002) observaram o mesmo comportamento ao avaliar a produtividade do milho na ausência e presença das plantas daninhas. Melo et al. (2001), ao analisar a 
interferência das daninhas na cultura da soja, constataram redução na produtividade da soja em todos os períodos de convivência soja-planta daninha.

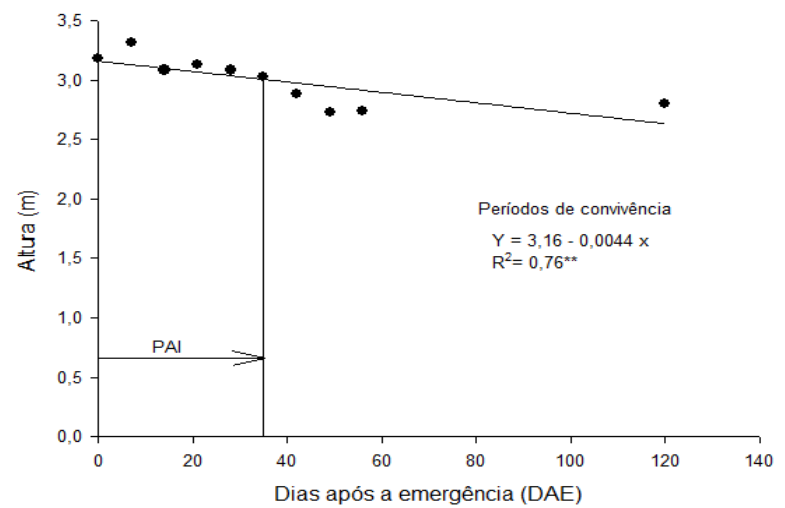

Figura 3. Altura de planta na cultura do sorgo sacarino em função dos períodos de convivência com as plantas daninhas. Nova Porteirinha-MG, 2012/13.

Considerando a altura de plantas, foi encontrado um PAI de 35 DAE (Figura 3), o que significa que a cultura pode permanecer na presença das plantas daninhas até os 35 DAE sem que sua altura seja afetada significativamente. Rossi et al. (1996), em experimento com a cultura do milho, verificaram que a interferência da comunidade infestante sobre a altura das plantas de milho manifestou-se aos 35 dias após a semeadura sendo que a partir dos 42 dias esta interferência reduziu, em média, $10 \%$ a altura das plantas. É válido salientar que esses períodos podem variar em função do potencial competitivo das espécies daninhas presentes, da densidade em que estas se encontram e das condições ambientais predominantes, que podem ou não ser favoráveis às plantas daninhas.

O espaçamento entre linhas e os períodos de controle de plantas daninhas não afetaram a altura das plantas. Snider et al. (2012) avaliaram cultivares de sorgo sacarino em diferentes arranjos de plantas e localidades dos Estados Unidos e observaram que o espaçamento também não afetou a altura das plantas. Todavia, Albuquerque et al. (2012), em experimentos conduzidos em Leme do Prado e em Jaíba-MG, constataram que 0 aumento do espaçamento favoreceu o incremento da altura das plantas.

Para a característica diâmetro de colmo, o período de controle não causou efeito significativo na cultura. Entretanto, houve resultados significativos para os espaçamentos e período de convivência (Figura 4). Os dados ajustaram-se à equação de regressão não linear.

Os valores de PAl encontrados foram 21 e 37 DAE, para os espaçamentos 0,5 e $0,7 \mathrm{~m}$, respectivamente. Nestes períodos a cultura pode permanecer na presença da comunidade infestante de plantas daninhas sem que haja alterações significativas no diâmetro dos colmos, desde que os espaçamentos sejam respeitados.

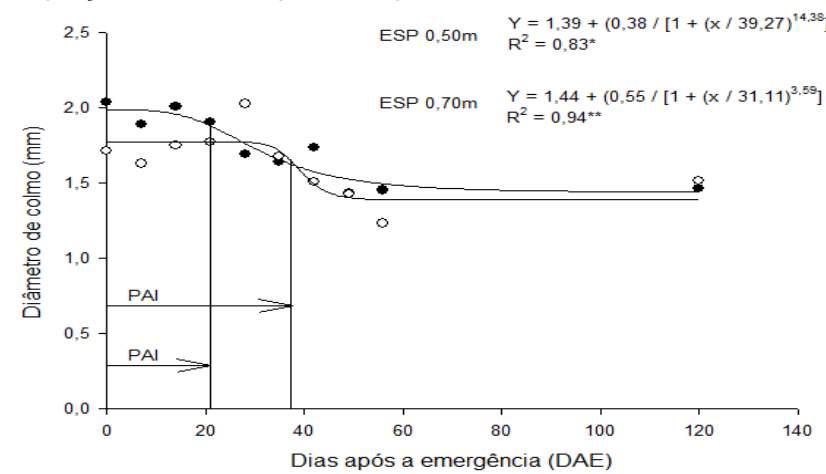

Figura 4. Diâmetro de colmo na cultura do sorgo sacarino em função dos períodos de convivência com as plantas daninhas. Nova Porteirinha-MG, 2012/13.

O diâmetro do colmo tende a diminuir com o aumento do período de convivência e, assim como citado anteriormente para a altura de plantas, esse comportamento pode ser explicado pela competição interespecífica da cultura com as plantas daninhas. Cabral et al. (2012) observaram em seu trabalho que, com o aumento dos períodos de convivência das plantas daninhas com o sorgo e redução dos períodos de controle, houve redução nas variáveis altura de plantas, diâmetro do colmo, massa de mil grãos do sorgo e do rendimento de grãos.

A produtividade de caldo, assim como o diâmetro de colmo e altura de plantas, não foi afetada significativamente pelo período de competição. Obtiveram-se, entretanto, resultados significativos para os espaçamentos em função dos períodos de convivência (Figura 5). Os dados foram ajustados a uma equação de regressão linear.

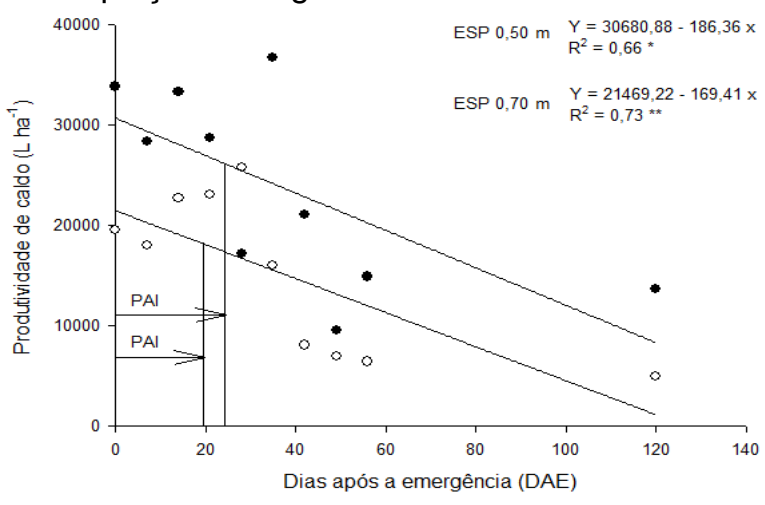

Figura 5. Produtividade de caldo na cultura do sorgo sacarino em função dos períodos de convivência com as plantas daninhas. Nova Porteirinha-MG, 2012/13.

Os valores de PAI encontrados foram de 19 e 24 DAE para os espaçamentos 0,5 e $0,7 \mathrm{~m}$, respectivamente. Infere-se, portanto, que a cultura 
pode permanecer na presença das plantas daninhas até os 19 e 24 DAE, nos seus respectivos espaçamentos, sem que a produtividade de caldo seja afetada significativamente.

A competição interespecífica entre a cultura e as plantas daninhas, assim como mencionado anteriormente para outras características, influenciou significativamente a produtividade de caldo, sendo possível observar a diminuição da produtividade de caldo com o aumento do período de competição.

\section{CONCLUSÕES}

O PAl é 19 e 24 DAE para o espaçamento 0,5 m e $0,7 \mathrm{~m}$, respectivamente.

O PTPI para produtividade de massa verde total é 17 e 10 DAE para os espaçamentos de 0,5 m e $0,7 \mathrm{~m}$, respectivamente. Não há PTPI para os demais parâmetros.

Não há PCPI para nenhum dos parâmetros avaliados (PAI > PTPI).

\section{AGRADECIMENTOS}

Os autores agradecem à Fundação de Amparo à Pesquisa de Minas Gerais (FAPEMIG) e à Coordenação de Aperfeiçoamento de Pessoal de Nível Superior (CAPES) pelo apoio financeiro e concessão de bolsas.

\section{REFERÊNCIAS}

ALBUQUERQUE, C. J. B. et al. Espaçamento entre fileiras e Densidade de semeadura do Sorgo forrageiro para a região norte de Minas Gerais. Ciência e Agrotecnologia, Lavras, v. 35, n. 3, 2011.

ALBUQUERQUE, C. J. B. et al. Sorgo sacarino em diferentes arranjos de plantas e localidades de Minas Gerais, brasil. Revista Brasileira de Milho e Sorgo, Sete lagoas,v. 11, n.1, p. 69-85, 2012.

BAUMHARDT, R. L.; HOWELL, T. A. Seeding practices, cultivar maturity, and irrigation effects on simulated grain sorghum yield. Agronomy Journal, Madison, v. 98, n. 2, p. $462-470.2006$.

CABRAL, P. H. R. et al. Interferência de plantas daninhas na cultura do sorgo cultivado em Rio Verde, GO. In: CONGRESSO DE PESQUISA E PÓS-GRADUAÇÃO DO
CAMPUS RIO VERDE DO IF GOIANO. 1, 2012. Rio Verde. Anais...2012. p. 3.

CARVALHO, F. T.; VELINI, E. D. Períodos de interferência de plantas daninhas na cultura da soja. I Cultivar IAC-11. Planta Daninha, Viçosa-MG, v. 19, n. 3, p. 317-322, 2001.

DURÃES. F. O. M. Sorgo sacarino: desenvolvimento de tecnologia agronômica. In.:Agroenergia em Revista. Ano 2, n. 3, 2011. Disponível em: http://ainfo.cnptia.embrapa.br/digital/bitstream/item/56043 /1/BolfeAgroeRevis.pdf. Acesso em: 22 agos. 2013.

JONES, O. R.; JOHNSON, G. L. Evaluation of a short season, high density production strategy for dryland sorghum. Texas: USDA-ARS, p. 97-101, 1997.

KOZLOWSKI, L. A. Período crítico de interferência das plantas daninhas na cultura do milho baseado na fenologia da cultura. Planta Daninha, Viçosa-MG, v. 20 , n. 3, p. 365-372, 2002.

MELO, H. B. et al. Interferência das plantas daninhas na cultura da soja cultivada em dois espaçamentos entre linhas. Planta Daninha, Viçosa-MG, v. 19, n. 2, p. 187191, 2001.

PITELLI, R. A.; DURIGAN, J. C. Terminologia para períodos de controle e de convivência de plantas daninhas em culturas anuais e bianuais. In: CONGRESSO BRASILEIRO DE HERBICIDAS E PLANTAS DANINHAS, 15., 1984, Belo Horizonte. Resumos... Belo Horizonte: SBHDE, 1984. p. 37.

ROSSI, I. H. et al. Interferência das plantas daninhas sobre algumas características agronômicas e a produtividade de sete cultivares de milho. Planta Daninha, Belo Horizonte, v. 14, n. 2, 1996.

SNIDER, J. L; RAPER, R. L; SCHWAB. The effect of row spacing and seeding rate on biomass production and plant stand characteristics of non-irrigated photoperiodsensitive sorghum. Industrial Crops and Products Tucson, v. 37, p. 527-535, 2012. 